BMJ Open Sport \& Exercise Medicine

\section{Bone health in elite Norwegian endurance cyclists and runners: a cross- sectional study}

To cite: Klomsten Andersen 0, Clarsen B, Garthe I, et al. Bone health in elite Norwegian endurance cyclists and runners: a cross-sectional study. BMJ Open Sport \& Exercise Medicine 2018:4:e000449. doi:10.1136/ bmjsem-2018-000449

- Additional material is published online only. To view please visit the journal online (http://dx.doi.org/10.1136/ bmjsem-2018-000449).

Accepted 25 November 2018

\section{ABSTRACT}

Background Athletes who compete in non-weightbearing activities such as swimming and cycling are at risk of developing low bone mineral density (BMD). Athletes in long-distance running are at risk of low BMD.

Objective (1) To evaluate the bone health in Norwegian male and female national elite road cyclists and middledistance and long-distance runners, and to identify cases of low BMD. (2) To identify possible risk factors associated with low BMD.

Methods Twenty-one runners ( 11 females and 10 males) and 19 road cyclists (7 females and 12 males) were enrolled in this cross-sectional study. Dual-energy X-ray absorptiometry measurement of BMD in total body, femoral neck and lumbar spine was measured. Participants completed a questionnaire regarding training, injuries, calcium intake and health variables.

Results The cyclists had lower BMD for all measured sites compared with the runners $(p \leq 0.05)$. Ten of 19 cyclists were classified as having low BMD according to American College of Sports Medicine criteria (Z-score $\leq-1$ ), despite reporting to train heavy resistance training on the lower extremities. Low BMD was site specific having occurred in the lumbar spine and the femoral neck and was not confined to females. Type of sport was the only factor significantly associated with low BMD.

Conclusion National elite Norwegian road cyclists had lower BMD compared with runners, and a large proportion was classified as having low BMD, despite having performed heavy resistance training. Interventions to increase BMD in this population should be considered.

\section{BACKGROUND}

Weight-bearing physical activity benefits the skeleton. ${ }^{1}$ About $10 \%$ of the skeleton is remodelled every year, and the relationship between bone resorption and bone remodelling depends substantially on the strain applied to the skeleton. ${ }^{2} 3$ Nutrition, represented by energy availability, also plays a key role for skeletal health. Low energy availability has been linked to suboptimal vitamin $\mathrm{D}$ and calcium status, which are essential for achieving peak bone mass (PBM). PBM represents the peak density of the skeleton and is usually achieved in the third decade

\section{What are the new findings?}

Elite road cyclists have lower bone mineral density (BMD) compared with middle-distance and long-distance elite runners, despite performing lower limb heavy resistance training. Ten of 19 cyclists were classified with low BMD.

- Low BMD was evident in male and female cyclists and affected the lumbar spine and the femoral neck.

- Type of sport was the only independent variable associated with low BMD.

How might it impact on clinical practice in the near future?

Our finding of prevalent low BMD in elite cyclists extends previous research and raises the question of whether these athletes will be at risk of osteoporosis.

- The study also raises the issue of site-specific screening for osteoporosis in this population.

of life. ${ }^{4}$ From that point on, bone mineral density (BMD) can only be maintained. Thus, weight-bearing activity and adequate energy availability during childhood and adolescent years are imperative for bone health later in life.

Non-weight-bearing activity, such as swimming and cycling, does not seem to promote gains in bone mass. ${ }^{5-7}$ Previous research has demonstrated high prevalence of low BMD in competitive cyclists. ${ }^{8-11}$ Furthermore, low BMD has been observed in elite middle-distance and long-distance runners, despite competing in a weight-bearing sport. ${ }^{12} 13$ Similar to cycling, performance in middle-distance and long-distance running is associated with low body mass. Low body mass and low energy availability have been linked to low BMD in several studies. ${ }^{14} 15$ Thus, it is possible that runners at elite level have a similar risk of developing low BMD, despite competing in a weight-bearing sport. 


\section{OBJECTIVE}

The primary objective of this present study was to compare BMD in total body, lumbar spine and femoral neck in male and female national elite road cyclists with male and female national elite middle-distance and long-distance runners and identify cases of low BMD, classified as having a Z-score of $\leq-1$ at one or more of the measured sites. The secondary objective was to identify possible risk factors associated with low BMD.

\section{METHODS}

\section{Study design}

We included 40 healthy male and female elite athletes (19 women and 21 males) competing in either road cycling $(\mathrm{n}=19)$ or middle-distance and long-distance running $(\mathrm{n}=21)$ in this cross-sectional study. BMD expressed as $\mathrm{gCal} / \mathrm{cm}^{2}$ was compared between groups. Three key BMD measurements were included: BMD for total body, lumbar spine and femoral neck.

\section{Recruitment}

The study sample was a convenience sample. The cycling teams were identified through Union Cycliste Internationale's (UCI) list of teams. UCI Continental Teams with connections to the Oslo area were invited to participate. Furthermore, riders at Pro Continental level or World Tour level who had conducted a dual-energy X-ray absorptiometry (DXA) scan at the Norwegian School of Sport Science or the Norwegian Olympic Training Centre within the last 3 years were invited. Twelve male cyclists chose to participate.

The female cyclists were identified by a list of riders competing at national level, given from the Norwegian Cycle Federation. Seven female cyclists who all had competed for the national team at some point during the last 3 years chose to participate.

The runners were recruited from the national team, national recruit team and elite amateur clubs in the Oslo area. The athletes received a personal email with an invitation and a detailed project description. Eleven female and 10 male middle-distance and long-distance runners chose to participate. Eight of the 22 runners were classified as long-distance runners (preferred distance $>3000 \mathrm{~m}$ ). Thirteen runners were classified as middle-distance runners (preferred distance 800-3000 $\mathrm{m})$. All participants received written informed consent and a detailed project description prior to the enrolment.

\section{Inclusion and exclusion criteria}

All athletes were between 18 and 35 years old and had competed at national level for a minimum of two consecutive years. Exclusion criteria included a history of smoking, diseases such as Crohn's disease, kidney diseases, rheumatic diseases or bone marrow diseases, which are known to affect the skeleton BMD. Furthermore, athletes were excluded if they had known family history of early-onset osteoporosis (prior to the age of $50)$.

\section{Measurements}

A DXA Lunar prodigy machine (GE Lunar Radiation, Madison, WI, USA, Software V.5.60) was used to measure fat-free mass, fat mass (FM), body mass index (BMI, $\left.\mathrm{kg} / \mathrm{m}^{2}\right)$ and BMD $\left(\mathrm{gCal} / \mathrm{cm}^{2}\right)$. Measurements included total body, lumbar spine (L2-L4) and femoral neck. Lumbar spine and femoral neck were included as they are the most common sites for osteoporotic fractures. ${ }^{16}$ The equipment was calibrated each morning prior to the first measurement. Anthropometrical measurements such as height and body mass were measured prior to the DXA scan (Seca scale, Mod: 8777021094, S/N: 5877248124885). Two scans were obtained using Hologic, Massachusetts (Discovery, S/N 83817). These scans were later converted to Lunar Prodigy by cross calibration, using a standardised equation. ${ }^{17}$

The participants attended the DXA scan between 07:00 and 10:00 in a fasting state. Twenty-two of the 40 scans were obtained at an earlier point, as part of an annual health scan performed by the Norwegian Olympic Training Center. Of these 22 scans, 16 were conducted in the previous year, with the remaining 6 a maximum of 3 years old.

Low BMD was defined as having a Z-score $\leq-1$ and osteoporosis was defined as Z-score $\leq-2$ with secondary clinical risk factors for fracture. These definitions are recommended by the American College of Sports Medicine when evaluating bone health in athletes, as athletes are more likely to have higher BMD compared with the general population. ${ }^{18}$ Furthermore, Z-scores are preferred over T-scores in healthy young males and females, because young individuals are most likely to have different anatomical bone structure compared with postmenopausal females. ${ }^{19}$

A questionnaire regarding training, injuries, calcium intake and health variables was answered by the participants using an online questionnaire (Questback, Oslo). The questionnaire consisted of two parts. Part 1 was a non-standardised questionnaire regarding training, previous fractures and health variables, including prevalence of secondary amenorrhoea. Secondary amenorrhoea is defined as the absence of menstrual cycles lasting for more than 3 months. ${ }^{20}$ The questionnaire was developed with guidance from experts within the fields of overuse injuries and nutrition. Part 2 was a standardised and validated questionnaire used to determine calcium intake per day. ${ }^{21}$

\section{Statistical analysis}

Statistical analyses were performed by using Statistical Package of Social Sciences (SPSS) V.24 and SAS (V.9.3). Demographical data are presented as mean and SD if normally distributed, or median (Mdn) and IQR if skewed. Student's t-test was applied on normally distributed data to compare means between two 
Table 1 Participants' characteristics with anthropometric measures for runners and cyclists. Values are presented as means and $\operatorname{SD}(n=40)$

\begin{tabular}{lcc}
\hline Measure & $\begin{array}{l}\text { Runners } \\
(\mathbf{n = 2 1 )}\end{array}$ & $\begin{array}{l}\text { Cyclists } \\
(\mathbf{n}=19)\end{array}$ \\
\hline Age (year) & $25.4(4.4)$ & $24.0(4.0)$ \\
\hline Height $(\mathrm{cm})$ & $178.1(11.8)$ & $177.1(7.6)$ \\
\hline Body mass $(\mathrm{kg})$ & $65.4(10.3)$ & $70.1(10.0)$ \\
\hline BMl $\left(\mathrm{kg} / \mathrm{m}^{2}\right)$ & $20.2(1.1)$ & $21.8(1.7)^{\star}$ \\
\hline FFM (\%) & $81(4)$ & $83(5)$ \\
\hline FM (\%) & $15(5)$ & $14(5)$ \\
\hline
\end{tabular}

${ }^{*} \mathrm{P} \leq 0.01$.

BMI, body mass index; FFM, fat-free mass; FM, fat mass.

groups. If skewed data, a non-parametric test was used. Binary univariate and multivariate logistical regression was applied to determine associations of low BMD. An alpha value of 0.05 was used for all measurements to determine statistical significance.

\section{Ethical considerations}

The study was reviewed and approved by the Regional Ethics Committee (REK ref 2016/1976). Each subject gave informed consent prior to enrolment in the study. Data collection was conducted in agreement with the Declaration of Helsinki-ethical principles for medical research involving human subjects. ${ }^{22}$

\section{RESULTS}

\section{Participants' anthropometrical characteristics}

Between-group analyses demonstrated that runners had lower BMI $(p \leq 0.001)$ compared with cyclists (table 1). There were no differences observed for any other demographic or anthropometrical measurements between the groups (table 1). Age and FM were not normally distributed for the cyclists; Mdn: 23.3 years, IQR: 3.4 years and Mdn: 12\%, IQR: 8\%, respectively.
Furthermore, body mass in runners was not normally distributed (Mdn: $64.0 \mathrm{~kg}$, IQR: $17.9 \mathrm{~kg}$ ).

\section{Participants' sports and health characteristics}

Table 2 shows participants' charateristics with sport, injuries and calcium measures. Cyclists had more training hours per year compared with runners $(p \leq 0.001)$. Calcium intake was similar in both groups. Sixteen of 17 cyclists reported to perform heavy resistance training on lower extremities for minimum of 2 consecutive months during the past 2 years. Furthermore, 15 of 16 reported to train heavy resistance training during the season of the DXA measurement. By contrast, only five runners reported the same. There was no difference in total fractures between cyclists and runners during their career. However, there were differences in type of fractures. Cyclists had higher cumulative incidence of acute fractures compared with runners $(p \leq 0.05)$. Conversely, runners had higher cumulative incidence of stress fractures compared with cyclists. The difference was not considered statistically significant. Age of starting to compete was not normally distributed for runners (Mdn: 16, IQR: 9).

\section{Participants' DXA characteristics}

Table 3 displays participants' DXA measures. Runners had significantly higher BMD $(\mathrm{p} \leq 0.05)$ for all measured sites. The largest difference was observed in total BMD $(p \leq 0.01)$. Low BMD, classified as having an age-matched Z-score of $\leq-1$ for minimum one of the measured sites, was found in 10 out of $19(53 \%)$ cyclists. ${ }^{18}$ Low BMD was not confined to females. Four of seven females and 6 of 12 males were classified with low BMD. None of the runners had an age-matched Z-score $\leq-1$. Of the 10 cyclists with low BMD, 7 had low BMD in the lumbar spine, 4 had low $\mathrm{BMD}$ in the femoral neck and 1 had low total BMD. Two cyclists had low BMD in more than one site. One cyclist was classified as osteoporotic (Z-score $\leq-2)$ in the lumbar

Table 2 Participants' characteristics with sport, injuries and calcium measures for runners and cyclists. Values are presented as means and SD $(n=38)$

\begin{tabular}{|c|c|c|}
\hline Measure & $\begin{array}{l}\text { Runners } \\
(n=21)\end{array}$ & $\begin{array}{l}\text { Cyclists } \\
(n=17) \ddagger^{*}\end{array}$ \\
\hline Started competing (age) & $18(5)$ & $16(1)$ \\
\hline Years competing & $7(3)$ & $7(3)$ \\
\hline Training hours (last year) & $549(170)^{\star \star}$ & $909(124)^{\star *}$ \\
\hline Calcium intake (mg/day) & $1503(674)$ & $1324(558)$ \\
\hline Number of athletes training HRT last 2 years & 5 & 16 \\
\hline Incident† total career acute fractures (\%) & $14^{*}$ & $59^{*}$ \\
\hline Incident† total career stress fractures (\%) & 48 & 12 \\
\hline
\end{tabular}

${ }^{*} \mathrm{P} \leq 0.05$. ${ }^{* *} \mathrm{P} \leq 0.01$.

†Cumulative incidence.

$\ddagger$ Two male cyclists did not respond to the questionnaire and were excluded from the present analysis.

HRT, heavy resistance training. 
Table 3 Dual-energy X-ray absorptiometry measurements expressed as bone mineral density $\left(\mathrm{g} / \mathrm{cm}^{2}\right)$ for runners and cyclists. Values are presented as means and SD $(n=40)$

\begin{tabular}{lll}
\hline Measure & $\begin{array}{l}\text { Runners } \\
(\mathbf{n}=\mathbf{2 1})\end{array}$ & $\begin{array}{l}\text { Cyclists } \\
(\mathbf{n = 1 9 )}\end{array}$ \\
\hline L-spine L2-L4 $\left(\mathrm{g} / \mathrm{cm}^{2}\right)$ & $1.267(0.094)^{\star} \dagger$ & $1.166(0.144)^{\star} \dagger$ \\
\hline Femoral neck $\left(\mathrm{g} / \mathrm{cm}^{2}\right)$ & $1.157(0.124)^{\star} \dagger$ & $1.052(0.123)^{\star} \dagger$ \\
\hline Total BMD $\left(\mathrm{g} / \mathrm{cm}^{2}\right)$ & $1.283(0.090)^{\star *}$ & $1.195(0.102)^{\star \star}$ \\
\hline Number of athletes with Z-score $\leq-1$ & 0 & 10 \\
\hline Number of athletes with Z-score $\leq-2$ & 0 & 1 \\
\hline
\end{tabular}

${ }^{*} \mathrm{P} \leq 0.05 ; \mathrm{P} \leq 0.01$.

†Missing data form one subject.

BMD, bone mineral density; L-spine, lumbar spine.

spine, with secondary clinical risk factors for fracture (previous spinal fracture). ${ }^{18}$

\section{Regression model}

Training hours in the previous year and cumulative incidence of acute fractures were significantly associated with low BMD (table 4). However, this relationship became insignificant when type of sport was entered as a covariate in the multivariate regression analysis. Furthermore, subgroup analysis revealed no significant relationship between secondary amenorrhoea and BMD in female athletes.

\section{DISCUSSION}

Our main finding was that compared with runners, cyclists had significantly lower BMD for all measured sites. This extends previous research done in the UK and the USA. ${ }^{523} 24$ Ten of 19 cyclists had BMD Z-scores $\leq-1$, despite that all, but one rider, reported to train heavy resistance training on the lower extremities in the previous 2 years. Low BMD was not confined to females. One male rider was classified as osteoporotic (Z-score $\leq-2)$ and he had secondary clinical risk factors for fracture (previous spinal fracture) ${ }^{18}$ In contrast, none of the runners had low BMD for any of the measured sites. The logistic regression model revealed no significant relationship with any independent variables, except type of sport. Thus, the difference in BMD observed between runners and cyclists appears to be attributed to the difference in mechanical strain exerted on the skeleton by gravitational forces.

\section{BMD and strength training}

There is currently limited research regarding the prevalence of strength training in elite cyclists and its effect on BMD. To the best of our knowledge, this is the first study to demonstrate that a high proportion of elite cyclists have BMD Z-scores $\leq-1$, despite reporting to train heavy resistance training on the lower extremities. It should be acknowledged that similar results have been reported

Table 4 Univariate binary logistic analysis of factors for low BMD for all participants (cyclists, $n=19 ;$ runners, $n=21$ )

\begin{tabular}{|c|c|c|c|}
\hline Factor & OR & $95 \% \mathrm{Cl}$ & $P$ value \\
\hline Age (year) & 1.068 & (0.907 to 1.257$)$ & 0.429 \\
\hline Height (cm) & 0.985 & (0.917 to 1.058$)$ & 0.683 \\
\hline Body mass (kg) & 0.998 & (0.932 to 1.069$)$ & 0.956 \\
\hline BMI $\left(\mathrm{kg} / \mathrm{m}^{2}\right)$ & 1.124 & (0.740 to 1.706$)$ & 0.583 \\
\hline FFM (\%) & 1.166 & (0.984 to 1.381$)$ & 0.077 \\
\hline FM (\%) & 0.903 & (0.767 to 1.064$)$ & 0.223 \\
\hline Started competing (age) $\dagger$ & 1.020 & (0.876 to 1.188 & 0.795 \\
\hline Years competing $†$ & 0.940 & (0.745 to 1.186$)$ & 0.603 \\
\hline Training hours (year) $\dagger$ & 1.006 & (1.001 to 1.011$)$ & $0.011^{*}$ \\
\hline $\mathrm{Ca}(\mathrm{mg} /$ day $) \dagger$ & 0.999 & (0.998 to 1.000$)$ & 0.205 \\
\hline Number of athletes training HRT last 2 years & 0.134 & (0.015 to 1.212$)$ & 0.074 \\
\hline Incident $\ddagger$ total career acute fractures $(\%) \dagger$ & 7.000 & (1.413 to 34.682$)$ & $0.017^{*}$ \\
\hline Incident $\ddagger$ total career stress fractures $(\%) \dagger$ & - & - & - \\
\hline
\end{tabular}

${ }^{*} \mathrm{P} \leq 0.05$;

†Missing data form two participants.

$\ddagger$ Cumulative incidence.

$\mathrm{BMD}$, bone mineral density; BMI, body mass index; Ca, calcium; FFM, fat-free mass; FM, fat mass; HRT, heavy resistance training. 
in recreational cyclists. ${ }^{10}$ Unfortunately, no information regarding intensity or frequency was given in the aforementioned study, or in ours, which makes it difficult to compare the results. Furthermore, the findings in the present study contradict recent research by Mathis and Caputo, ${ }^{25}$ who found that resistance training was positively associated with BMD in the lumbar spine and hip bone in recreational male road cyclists (age 31-69 years). It is possible that the large amount of non-weight-bearing training conducted by the athletes in the present study attenuated the osteogenic effect elicited by the resistance training. Most studies documenting a beneficial effect of resistance training on bone mass are longitudinal studies, lasting for minimum 7-12 months, with two to three sessions per week. ${ }^{26}{ }^{27}$ Usually, cyclists perform strength training during off-season, which is the winter months from October to January. Thus, 2-4 months of strength training might not be sufficient to elicit the bone modelling process.

\section{Low BMD (Z-score <-1) was site specific}

The prevalence of low BMD in the present study was site specific, having occurred in the lumbar spine and the femoral neck. In contrast, only one rider had low total body BMD. Previous research has shown that both the lumbar spine and the femoral neck are risk areas of low BMD in cyclists. ${ }^{9112324}$ The spine and, to some extent, the femoral neck consist of trabecular bone. This has a higher metabolism compared with cortical bone, which is the main constituent of the skeleton. Thus, it is hypothesised that trabecular bone responds to loading and unloading earlier than cortical bone.

\section{Cycling performance depends on power-to-weight ratio}

Elite cyclists, as well as long-distance runners, have a reputation of an unhealthy focus on leanness and low body mass. Sundgot-Borgen and Torstveit ${ }^{28}$ reported that $8 \%$ of Norwegian male athletes suffered from eating disorders, and an alternative terminology to the female athlete triad, relative energy deficiency in sport (RED-S), has been proposed, in part to acknowledge male athletes. ${ }^{1}$ The syndrome involves energy deficit as the main component. In cycling, the most important performance marker is power-to-weight ratio, or watt per kilogram. Thus, a reduction in body mass will increase cycling performance if power is sustained. There are reports of cyclists trying to enhance their power-to-weight ratio at the expense of energy intake.$^{29}$ Furthermore, due to prolonged exercise, cyclists may be at risk of having suboptimal energy intake during training, which has been associated with low bone mass. ${ }^{130}$ Unfortunately, eating habits and the prevalence of RED-S are unknown in our sample.

Calcium intake is closely linked to the total energy intake. In the present study, all athletes had an adequate calcium intake and calcium was not associated with low BMD in cyclists. This is consistent with previous research, which has not been able to demonstrate a significant relationship between calcium intake and BMD in cyclists. ${ }^{7923}$ Recent research has shifted focus from total calcium consumption to the timing of calcium intake. The dermal loss of calcium during prolonged exercise has shown to elevate the expression of parathyroid hormone (PTH) and cross linked C-telopeptide of type 1 collagen (CTX-1) in serum, which are biomarkers associated with higher osteoclastic activity and bone loss. Haakonssen and colleagues ${ }^{31}$ demonstrated that a calcium-rich meal $90 \mathrm{~min}$ prior to intensive exercise decreased the expression of PTH and CTX-1. This is especially relevant for cyclists who often compete for several hours in warm climate and the dermal loss of calcium is thought to be substantial. We did not investigate the timing of calcium intake in our study.

\section{Secondary amenorrhoea}

Energy deficits have been linked to secondary amenorrhoea in female athletes. ${ }^{32}$ Sixty-seven per cent of the female athletes in the present study reported that they, at some point during their career, had experienced secondary amenorrhoea. The distribution was similar in cyclists and runners. We found no relationship between secondary amenorrhoea and prevalence of low BMD. Furthermore, none of the female runners with secondary amenorrhoea and previous stress fractures displayed low levels of BMD. This is surprising as both stress fractures and secondary amenorrhoea have been associated with low BMD in previous research. ${ }^{123-35}$ Thus, it is possible that our study was underpowered to show this relationship. In addition, several other nutritional and hormonal factors, such as vitamin D, oestrogen, steroidal contraceptives, cortisol and testosterone, are thought to influence BMD. ${ }^{36-38}$ Unfortunately, we were not able to measure these markers, which potentially could have given valuable insight to the differences observed in BMD.

\section{Strength and limitations}

The sample consisted of homogenous and highly trained individuals. Note that all cyclists competed at an international level. Thus, it is likely that they share similar characteristics of elite cyclists in other countries, making the results of the present study generalisable to elite Caucasian cyclists. Although elite athletes are more challenging to recruit than lower level/recreational athletes, we chose to limit our inclusion to a homogenous group of high-level athletes, at the expense of a larger sample size and statistical limitations. This priority may have resulted in that some associations between independent variables and BMD being overlooked. In this study, we did not identify any runners with BMD Z-scores $\leq-1$. This could speak to high-quality management and education of these athletes in Norway's specialised elite training programme (Olympiatoppen). It would be erroneous to conclude that elite runners are not at risk of having low BMD. A study including larger number of participants would be able to estimate the actual difference in risk between groups more accurately. 
The participants in the present study are likely to be lighter and smaller compared with the norms in the DXA database. DXA measures BMD in a two-dimensional frame, and is influenced by bone size. Larger bones will have higher areal BMD, compared with smaller bones, even with the same volumetric density. ${ }^{39}$ To account for this confounding effect, bone mineral apparent density has been introduced, and it is recommended to be applied when assessing BMD in children. ${ }^{39-41}$ In the present study, we did not correct for bone size, which could result in an overdiagnosing of low BMD. However, the participants in the present study cannot be regarded as individuals with short stature. Thus, it is debatable how meaningful such an adjustment would have been. ${ }^{42} 43$ Future research should consider the use of quantitative $\mathrm{CT}$, as it measures BMD in a three-dimensional frame and can more accurately measure bone microarchitecture and bone strength. ${ }^{44}$

The DXA scans were obtained by using several, but experienced technicians. All but two DXA scans were performed on the same equipment (Lunar Prodigy). The remaining two were measured on a Hologic scanner. However, a rerun of the analysis excluding the Hologic results did not alter our results. Furthermore, all health, nutrition and fracture history was based on a questionnaire. Thus, a potential recall bias should be acknowledged.

\section{Practical implications}

Our findings extend previous studies that reported a proportion of cyclists to have low BMD (Z-score $\leq-1$ ). The novelty is, however, that elite cyclists report to have been performing heavy resistance training and still display low BMD. Unfortunately, due to the study design, it is not possible to assess whether the strength training performed has had a positive effect on the skeleton.

Little is known regarding the prevalence of osteoporotic fractures later in life in elite cyclists, or if low BMD (Z-score $\leq-1$ ) is associated with an increased prevalence of fractures in this population. However, what is known from research is that competitive cyclists display lower levels of BMD compared with their active peers already during adolescence. ${ }^{45}$ Furthermore, both male and female cyclists have been observed to lose as much as $1 \%-1.5 \%$ of BMD in the lumbar spine and femoral neck during the course of a competitive season. ${ }^{11}$ This corresponds to the accelerated bone loss observed in postmenopausal women. ${ }^{46}$ Moreover, a higher prevalence of osteopenia and osteoporosis has been displayed in highly trained master cyclists, when compared with inactive controls $\left(89.5 \%\right.$ vs $61.1 \%$, respectively). ${ }^{47}$ Although a Z-score $\leq-1$ cannot be considered a disease, existing evidence warrants close monitoring of cyclists with low BMD. Further, it raises the question whether interventions to increase BMD in this population should be considered.

\section{CONCLUSION}

National elite Norwegian road cyclists had lower BMD compared with runners, and a large proportion was classified as having low BMD, despite having performed heavy resistance training. Interventions to increase BMD in this population should be considered.

Acknowledgements We express our very great appreciation to all the participating athletes and to Erling Hisdal for valuable help in the recruitment process.

Contributors OKA contributed to the original idea of this study and drafted the manuscript. TS was the main supervisor and senior researcher of the study. All statistical analyses were performed by OKA and BC. All authors commented and contributed with important intellectual content and final approval of the version to be published.

Funding The authors have not declared a specific grant for this research from any funding agency in the public, commercial or not-for-profit sectors.

Competing interests None declared.

Patient consent for publication Not required.

Ethics approval The study was reviewed and approved by the Regional Ethics Committee (REK ref 2016/1976).

Provenance and peer review Not commissioned; internally peer reviewed.

Data sharing statement Statistical analyses and data sets are available from the corresponding author.

Open access This is an open access article distributed in accordance with the Creative Commons Attribution Non Commercial (CC BY-NC 4.0) license, which permits others to distribute, remix, adapt, build upon this work non-commercially, and license their derivative works on different terms, provided the original work is properly cited, appropriate credit is given, any changes made indicated, and the use is non-commercial. See: http://creativecommons.org/licenses/by-nc/4.0/

\section{REFERENCES}

1. Mountjoy M, Sundgot-Borgen J, Burke L, et al. The IOC consensus statement: beyond the female athlete triad--Relative Energy Deficiency in Sport (RED-S). Br J Sports Med 2014;48:491-7.

2. Rubin CT, Lanyon LE. Regulation of bone formation by applied dynamic loads. J Bone Joint Surg Am 1984;66:397-402.

3. Frost HM. Bone "mass" and the "mechanostat": a proposal. Anat Rec 1987;219:1-9.

4. Bonjour J-P, Theintz G, Law F, et al. Peak bone mass. Osteoporosis International 1994;4-S7-13.

5. Stewart AD, Hannan J. Total and regional bone density in male runners, cyclists, and controls. Med Sci Sports Exerc 2000;32:1373-7.

6. Medelli J, Lounana J, Menuet JJ, et al. Is osteopenia a health risk in professional cyclists? J Clin Densitom 2009;12:28-34.

7. Campion F, Nevill AM, Karlsson MK, et al. Bone status in professional cyclists. Int J Sports Med 2010;31:511-5.

8. Nichols JF, Palmer JE, Levy SS. Low bone mineral density in highly trained male master cyclists. Osteoporos Int 2003;14:644-9.

9. Barry DW, Kohrt WM. BMD decreases over the course of a year in competitive male cyclists. Journal of Bone and Mineral Research 2008;23:484-91.

10. Smathers AM, Bemben MG, Bemben DA. Bone density comparisons in male competitive road cyclists and untrained controls. Med Sci Sports Exerc 2009;41:290-6.

11. Sherk VD, Barry DW, Villalon KL, et al. Bone loss over 1 year of training and competition in female cyclists. Clin J Sport Med 2014;24:331-6.

12. Burrows $M$, Bird S. The physiology of the highly trained female endurance runner. Sports Med 2000;30:281-300.

13. Hind K, Truscott JG, Evans JA. Low lumbar spine bone mineral density in both male and female endurance runners. Bone 2006;39:880-5.

14. Gibbs JC, Nattiv A, Barrack MT, et al. Low bone density risk is higher in exercising women with multiple triad risk factors. Med Sci Sports Exerc 2014;46:167-76.

15. Tenforde AS, Fredericson M, Sayres LC, et al. Identifying sexspecific risk factors for low bone mineral density in adolescent runners. Am J Sports Med 2015;43:1494-504. 
16. Leib ES, Lewiecki EM, Binkley N, et al. Official positions of the international society for clinical densitometry. J Clin Densitom 2004;7:1-5.

17. Genant HK, Grampp S, Glüer CC, et al. Universal standardization for dual X-ray absorptiometry: Patient and phantom cross-calibration results. Journal of Bone and Mineral Research 2009;9:1503-14.

18. Nattiv A, Loucks AB, Manore MM, et al. American college of sports medicine position stand. The female athlete triad. Med Sci Sports Exerc 2007;39:1867-82

19. Lewiecki EM, Lane NE. Common mistakes in the clinical use of bone mineral density testing. Nat Clin Pract Rheumatol 2008;4:667-74

20. Practice Committee of American Society for Reproductive Medicine. Current evaluation of amenorrhea. Fertil Steril 2008;90:S219-S225.

21. Macdonald HM, Garland A, Burr J, et al. Validation of a short questionnaire for estimating dietary calcium intakes. Osteoporos Int 2014;25:1765-73.

22. World Medical Association. World medical association declaration of Helsinki: ethical principles for medical research involving human subjects. JAMA 2013;310:2191-4.

23. Beshgetoor D, Nichols JF, Rego I. Effect of training mode and calcium intake on bone mineral density in female master cyclist, runners, and non-athletes. Int J Sport Nutr Exerc Metab 2000;10:290-301.

24. Rector RS, Rogers R, Ruebel M, et al. Participation in road cycling vs running is associated with lower bone mineral density in men. Metabolism 2008;57:226-32.

25. Mathis SL, Caputo JL. Resistance training is associated with higher lumbar spine and hip bone mineral density in competitive male cyclists. J Strength Cond Res 2018;32:274-9.

26. Hind K, Burrows M. Weight-bearing exercise and bone mineral accrual in children and adolescents: a review of controlled trials. Bone 2007; 40:14-27.

27. Layne JE, Nelson ME. The effects of progressive resistance training on bone density: a review. Med Sci Sports Exerc 1999;31:25-30.

28. Sundgot-Borgen J, Torstveit MK. Prevalence of eating disorders in elite athletes is higher than in the general population. Clin J Sport Med 2004;14:25-32.

29. Ferguson LM, Rossi KA, Ward E, et al. Effects of caloric restriction and overnight fasting on cycling endurance performance. J Strength Cond Res 2009;23:560-70.

30. Vogt S, Heinrich L, Schumacher YO, et al. Energy intake and energy expenditure of elite cyclists during preseason training. Int $J$ Sports Med 2005;26:701-6.

31. Haakonssen EC, Ross ML, Knight EJ, et al. The effects of a calciumrich pre-exercise meal on biomarkers of calcium homeostasis in competitive female cyclists: a randomised crossover trial. PLoS One 2015;10:e0123302.

32. Pauli SA, Berga SL. Athletic amenorrhea: energy deficit or psychogenic challenge? Ann N Y Acad Sci 2010;1205:33-8.
33. Chen YT, Tenforde AS, Fredericson M. Update on stress fractures in female athletes: epidemiology, treatment, and prevention. Curr Rev Musculoskelet Med 2013;6:173-81.

34. Haenggi W, Casez JP, Birkhaeuser MH, et al. Bone mineral density in young women with long-standing amenorrhea: limited effect of hormone replacement therapy with ethinylestradiol and desogestrel. Osteoporos Int 1994:4:99-103.

35. Lauder TD, Dixit S, Pezzin LE, et al. The relation between stress fractures and bone mineral density: evidence from active-duty army women. Arch Phys Med Rehabil 2000;81:73-9.

36. De Souza MJ, West SL, Jamal SA, et al. The presence of both an energy deficiency and estrogen deficiency exacerbate alterations of bone metabolism in exercising women. Bone 2008;43:140-8.

37. Fernández-Garcia B, Lucía A, Hoyos J, et al. The response of sexual and stress hormones of male pro-cyclists during continuous intense competition. Int J Sports Med 2002;23:555-60.

38. Lappe J, Cullen D, Haynatzki G, et al. Calcium and vitamin d supplementation decreases incidence of stress fractures in female navy recruits. J Bone Miner Res 2008;23:741-9.

39. Carter DR, Bouxsein ML, Marcus R. New approaches for interpreting projected bone densitometry data. J Bone Miner Res 1992;7:137-45

40. Weaver CM, Gordon CM, Janz KF, et al. The National osteoporosis foundation's position statement on peak bone mass development and lifestyle factors: a systematic review and implementation recommendations. Osteoporos Int 2016;27:1281-386.

41. Crabtree NJ, Arabi A, Bachrach LK, et al. Dual-energy X-ray absorptiometry interpretation and reporting in children and adolescents: the revised 2013 ISCD pediatric official positions. J Clin Densitom 2014;17:225-42.

42. Short DF, Zemel BS, Gilsanz V, et al. Fitting of bone mineral density with consideration of anthropometric parameters. Osteoporos Int 2011:22:1047-57.

43. Zemel BS, Leonard MB, Kelly A, et al. Height adjustment in assessing dual energy $x$-ray absorptiometry measurements of bone mass and density in children. J Clin Endocrinol Metab 2010;95:1265-73.

44. Adams JE. Quantitative computed tomography. Eur J Radiol 2009;71:415-24.

45. Olmedillas H, González-Agüero A, Moreno LA, et al. Bone related health status in adolescent cyclists. PLoS One 2011;6:e24841.

46. Sowers MR, Zheng $\mathrm{H}$, Greendale GA, et al. Changes in bone resorption across the menopause transition: effects of reproductive hormones, body size, and ethnicity. J Clin Endocrinol Metab 2013;98:2854-63.

47. Nichols JF, Rauh MJ. Longitudinal changes in bone mineral density in male master cyclists and nonathletes. J Strength Cond Res 2011;25:727-34. 